phosphoric ester. The latter compound would show the same fluorescence as flavin itself, but during the isolation process it might have lost the phosphoric acid group.

Recently Emmerie ${ }^{7}$ has shown that flavin can be easily separated from flavin phosphoric acid by means of certain solvents. Benzyl alcohol, for example, dissolves flavin ${ }^{8}$ but not the flavin phosphoric ester.

The application of this simple principle to the present problem showed us soon that the flavin of fish eyes was free flavin and not flavin phosphate. The eye of a big cod was detached immediately after killing, frozen in solid carbon dioxide, and the separated retina and pigment layer were extracted by grinding with ice water. By shaking the sharply centrifuged yellow solution with benzylalcohol three times the flavin was completely extracted. When lactoflavin phosphoric acid* was added to the water extract of the pigment layer of another eye it remained in the water phase after a similar treat. ment with benzyl alcohol.

The occurrence of free flavin in the eye suggests that flavin phosphate taken up with the food is dephosphorylated for its deposition in the eye. According to $\mathrm{Kuhn}$, free flavin may also form an active compound with the protein part of flavin enzyme. This compound, contrary to the flavin enzyme, which is a flavin phosphate protein compound $^{10}$, is highly dissociated into its inactive components. The occurrence of free flavin suggests, therefore, that its function in the eye may be not that of a redox catalyst but that it may take part in the visual processes by means of its photochemical properties ${ }^{11,12}$, as fluoreseence and light sensitivity.

Biochemical Institute,

E. AdLER.

University, Stockholm.

H. v. EULER. March 28.

* We are indebted to Prof. P. Karrer for the lactoflavin phosphate used in this experiment.

${ }^{1}$ Euler and Adler, Svenska Vetenskapsakad. Arkiv f. kemi, 11, B, No. 21 (1933).

2 Euler and Adler, Z. physiol. Chem., 228, 105 (1934).

3 Euler and Adler, Z, physiol. Chem., 228, 1 (1934).

- Euler, Hellström and Adler, $Z$. vergl. Physiol., 21, 739 (1935).

- Karrer, Euler and Schöpp, Sv. Vet. Ark. f. kemi, 11, B, No. 54 (1935).

- Euler, Adler and Schlötzer, Z. physiol. Chem., 226, 87 (1934).

7 Emmerie, Nature, 141, 416 (1938).

${ }^{8}$ Greene and Black, J. Amer. Chem. Soc., 59, 1820 (1937).

- Kuhn and Rudy, Ber. deutsch. chem. Ges., 69, 2557 (1936).

10 Theorell, Biochem. Z., 275, 344 (1935).

21 Theorell, Biochem, $Z$., 279, 186 (1935).

"Zewi, Finska Läkaresällsk. Handl., 80, 923 (1937).

\section{Spore Formation in a Vibrio}

WhILST nitrate reduction is a property common to a large group of bacteria belonging to very divergent genera (Micrococcus, Pseudomonas, Bacillus, etc.), all investigators who have thoroughly studied the important natural process of sulphate reduction agree that the causal organism is in all cases the strictly anærobic typically vibrio-shaped bacterium first described by Beijerinck in $1895^{1}$. It is true that the strains isolated sometimes show slight mutual differences which have led to the creation of one or two separate species or varieties, but this circum. stance does not detract from the remarkable fact that these strictly anærobic representatives of a genus which until now has generally been considered to be non-spore-forming (apart from a few quite equivocal cases in the older literature) are almost universally distributed in Nature.
Seen in this light, it seems worth reporting that during investigations carried out in the last six months, decisive proof has been obtained that spore formation occurs in Vibrio desulfuricans. This fact has first been ascertained for pure cultures of the thermophilic variety earlier described by Elion and by Baars. It was then found that soil, canal and ditch mud, and sewage after having been heated for 30 minutes in boiling water, readily yielded active cultures of sulphate-reducing vibrios, when inoculated into the usual lactate enrichment medium both at $55^{\circ} \mathrm{C}$. and at $30^{\circ} \mathrm{C}$. In these cultures various morphological variations occur leading ultimately to the formation of spindle-shaped or slightly bent cells with sub-terminal, highly refractive spores about $1.7 \times 1 \cdot 3 \mu$ in size. Subcultures could be obtained by transferring these original cultures after they had been heated in boiling water for an hour. Cells in these cultures were the typical actively motile vibrios and spirals. Pure cultures obtained by repeated plating continue to produce spores when grown in various media in the temperature region between $45^{\circ}-55^{\circ} \mathrm{C}$. However, continued cultivation in the lactate medium at temperatures below $40^{\circ} \mathrm{C}$. makes the cultures rapidly asporogenous, and this circumstance may well be responsible for the fact that spore formation in this species has been entirely overlooked until now, even by such a highly competent bacteriologist as Beijerinck.

The new generic name Sporovibrio is proposed for the sporulating, anærobic, Gram-negative, curved bacteria of this type.

The circumstance that under certain conditions cultures of Vibrio desulfuricans show a perfect and very regular spirillum-shape-hence the name of Spirillum desulfuricans as originally proposed by Beijerinck-makes it seem worth while to carry out renewed investigations regarding the spore-forming ability of other representatives of both the genera Spirillum and Vibrio (Vibrio cholerce!).

Laboratorium voor Microbiologie, R. L. Starkey.

Technische Hoogeschool, Delft. March 28.

${ }^{1}$ Beijerinck, M. W., Centr. Bakt. (ii), 1, 1-9, 49-59, 104-114 (1895). For a review of later publications the reader is referred to $J$. K. Baars, "Over sulfaatreductie door bacteriën" (Delft, 1930); see also H. J. Bacteria" (London, 1936).

\section{Ounce Molecular Weight of a Gas}

Ir does not appear to be generally recognized that an 'ounce molecular weight' of a gas will fill 22.4 cubic feet under a pressure of one atmosphere and at $0^{\circ} \mathrm{C}$. This relationship is very useful as a starting point in many calculations of gas quantities in English units, and it might well be inserted in textbooks of physics and chemistry at the same time as the more conventional statement involving grammolecular and litre units is presented.

The existence of this relation must have been noted by various workers, but it has undoubtedly not received the prominence and general use which it deserves. Since noting it myself independently in 1920, I have always found that its existence and use have been regarded as surprising and novel by any to whom I have mentioned it, until recently when $I$ have been informed that the relation has in fact received text-book publication and indeed appears in the form of a problem set on p. 999 of Partington's "Textbook of Inorganic Chemistry". 